\title{
Dossiê: "A educação em rede e a inovação responsáveis em tempos de pandemia".
}

\author{
Marcio Vieira de Souza ${ }^{1}$
}

\section{RESUMO}

Este dossiê tem por objetivo disseminar pesquisas empíricas e teóricas sobre a educação em rede e a inovação responsáveis em tempos de pandemia. Assim, apresenta-se aqui, além do contexto no qual resultou nesta oportunidade de refletir acerca do papel da educação em rede e a inovação responsáveis durante o período pandêmico, uma breve descrição sobre os temas abordados nos diversos artigos e relatos que compuseram este dossiê. Cabe destacar que tais investigações foram produzidas a partir do evento IV Encontro Internacional de Inovação na Educação, mais conhecido como encontro do "Educação Fora da Caixa", realizado em Florianópolis em 2021, no qual posibilitou discussões relevantes sobre os principais avanços no campo da inovação educacional com o intuito de contribuir para os desafios em época de pandemia.

Palavras-chave: Rede. Educação. Conhecimento. Inovação. 


\section{APRESENTAÇÃO}

Com a pandemia e o consequente isolamento social, com as incertezas e desafios na saúde pública e na ciência em nível global, vivemos uma época de quebra dos paradigmas em vários campos de conhecimento. No trabalho e na educação, a aceleração dos processos de inovação acarreta um impacto massivo das tecnologias da informação e comunicação, bem como das mídias do conhecimento e tem trazido instigações em vários níveis: do local ao global; de inovações tecnológicas e metodológicas, epistemológicas e teóricas. Foi com essa chamada que a revista EmRede convidou pesquisadores para participar deste dossiê.

O convite para organizarmos este projeto de revista temática ocorreu durante o processo de construção do IV Encontro Internacional de Inovação na Educação, mais conhecido como encontro do "Educação Fora da Caixa".

O evento realizado de forma bianual em Florianópolis já se consolidou como um importante fórum no cenário da inovação na educação no país. Evento pioneiro foi realizado em 2015 como uma iniciativa de dois grupos de pesquisa da Universidade Federal de Santa Catarina-UFSC: o VIA - Estação do conhecimento e Grupo de pesquisa em Mídia e Conhecimento (GPMC-CNPq/UFSC) em parceria com vários atores da tríplice hélice. Em 2017, foi organizado o segundo encontro, já com uma visão internacional. Uma terceira edição, em 2019, ocorreu em parceria com o SEBRAE Santa Catarina e Nacional, que aconteceu juntamente com o $3^{\circ}$ ConheCer - evento de educação do SEBRAE - no Centro de Eventos de Florianópolis (TEIXEIRA; SOUZA, 2018). O evento gratuito atraiu mais de 2 mil inscritos de todo - Brasil, basicamente pessoas da área educacional ávidas por discussões sobre os desafios de inovar com responsabilidade social e compromisso com a qualidade da educação. A cada edição, o evento cresce e fortalece os laços das redes constituídas, bem como atrai parcerias nacionais e internacionais.

Com o agravamento da pandemia de Covid-19, em março de 2020, inovar em educação e pensar fora da caixa tem sido cada vez mais necessário. Face aos inúmeros desafios enfrentados pelos sistemas de ensino e pelos sujeitos que os constituem, reflexões sobre a transposição dos tempos e dos lugares de ensino-aprendizagem têm-se tornado objeto de inúmeras pesquisas e de questionamentos cotidianos por parte de docentes, discentes e gestores da educação em seus diversos níveis de ensino (TEIXEIRA et al., 2021).

Nessa esteira, o IV Encontro Internacional de Inovação na Educação - o Educação Fora da Caixa - abriu espaço para que o tema Inovação na educação em tempos de pandemia pudesse ser abordado por diferentes atores do cenário educacional, com a intenção de promover debates, apresentar alternativas e projetos, discutir metodologias de ensinoaprendizagem e refletir - não só, mas também - sobre a apropriação crítica e responsável das Tecnologias Digitais da Informação e Comunicação para a educação. Realizado de forma totalmente on-line nos dias 14 e 15 de junho de 2021, o evento contou mais uma vez com a parceria entre a Universidade Federal de Santa Catarina e o SEBRAE - Santa Catarina.

Em meio à pandemia de Covid-19, vários desafios estavam colocados e, por isso, esta edição teve como tema Educação inovadora em tempos de pandemia. Para atingir esse 
objetivo, e com apoio do SEBRAE-SC, foi projetada uma plataforma de ambiente virtual de aprendizagem (AVA) massivo, com streaming e transmissão ao vivo, controlada e com certa interatividade, modelada com uma meta de 5.000 participantes inscritos. Essa meta foi superada com a inscrição de 5.659 participantes. As inscrições foram gratuitas. 0 evento online ocorreu com a realização de 16 painéis compostos por 47 especialistas nacionais e internacionais, abordando debates nas seguintes temáticas: Educação em Rede; Ensino Empreendedor; Ensino-Aprendizagem e Pesquisa e Inovação Responsáveis. Esse grande movimento acaba gerando um processo de mobilização em rede de várias articulações préexistentes como uma forma de rede de redes, ou seja, vários produtos, ferramentas e troca de experiências acontecem ao longo do processo de construção e sistematização do conhecimento gerado entre um e outro encontro bianual. A dinâmica desse evento acontece dentro de um ecossistema de inovação, como uma rede que mobiliza diferentes atores sociais para aproximar a ciência da sociedade, contribuir na formação de professores de diferentes áreas do conhecimento e promover aprendizagens inovadoras e inclusivas para estudantes com e sem acesso às Tecnologias de Informação e Comunicação (OKADA et al., 2021).

Entre os produtos significativos que formam a ligação dos movimentos podemos dizer que estão os seis livros e os anais dos eventos, assim como os vídeos e transmissões on-line que em sua maioria são gravados e disponibilizados na interneti. Talvez, no entanto, o que com a pandemia tem ganhado bastante força e significação é o fortalecimento de redes temáticas vinculadas à educação e suas parcerias com o evento. Produtos paralelos inspirados nessas redes, como este dossiê, são elementos importantes nessas ligações temáticas. Um exemplo significativo nesse sentido é a Rede RRI-Brasil que possui grupos de pesquisa em todas as regiões geográficas do Brasil, do Norte ao Sul, e se articula com a Open University da Inglaterra com conexão com alguns projetos nacionais e internacionais. Vários atores, pesquisadores dessa rede em construção, têm participado como colaboradores, autores, painelistas e palestrantes do Edu Fora da Caixa. Temáticas e conceitos emergentes para inovar a educação, com base nos trabalhos da UNESCO para que sejam alcançadas as diretrizes do Objetivo de Desenvolvimento Sustentável 4 (ODS 4), da Agenda 2030, para uma Educação 2030 com Escolarização Aberta, Educação Aberta, Acesso Aberto, pensando a inovação, a educação e a pesquisa de forma responsáveis (RRI) e em rede. Esses temas foram dialogados e refletidos no Edu Fora da Caixa e estão aqui representados, por exemplo, nos artigos 1, 2, 5 e 6 . Ao ler esses artigos, vocês também terão a perspectiva de que os pesquisadores estão analisando e dando importância para experiências regionais, locais, mas estão pensando, agindo e entendendo que precisamos de soluções globais, transnacionais e que vivemos em uma só casa, o planeta água.

As práticas de tais artigos, escritos por articulistas que pesquisam na Grã Bretanha Open University - com brasileiros, e na Espanha - UNED - com brasileiros, bolivianos e argentinos, faz com que lembremos aqui do porquê temos neste dossiê um artigo em inglês, três em espanhol e os demais em português. A riqueza das articulações e troca de experiências dessas redes nos faz citar aqui uma outra rede significativa que trabalha dentro da perspectiva dos estudos das Ciências das redes, tema cada vez mais importante para se compreender esse mundo super conectado e a educação dentro dele.

Como sempre dizemos, se estamos numa sociedade em rede (CASTELLS,2010), a educação que está dentro dessa sociedade tem que ser analisada como uma rede. Portanto, 
toda a educação está em rede e precisamos diagnosticar que tipo de rede ela é: centralizada, descentralizada, distribuída? Temos de pensar que tipo de educação em rede queremos?

A educação em rede em tempos de Fake News deve promover o letramento informacional e a ética da informação (MÜLLER; SOUZA, 2018). Uma educação em rede democrática exige o fortalecimento da cibercidadania, utilizando as mídias do conhecimento de forma transformadora e crítica, visando o bem social. Uma educação em rede democrática deve ser entendida como um espaço de diálogo, interatividade, reelaboração de informações, transformando o conhecimento em instrumento de cibercidadania (SOUZA, 2015). Portanto, no nosso entender uma educação em rede democrática deve ter as seguintes perspectivas: ser um espaço de diálogo, ter interatividade, ver a educação sob o olhar da ciência das redes, utilizar as mídias digitais e do conhecimento de forma crítica e transformadora e estar imersa na cibercultura (MÜLLER; SOUZA, 2020).

Acreditamos que as reflexões aqui contidas mirem em uma educação em rede democrática e que esse dossiê pode contribuir nesse sentido. Temos os artigos 3 e 4 de parceiros argentinos, os quais participam da Associação Latino Americana de Análise de Redes Sociais (ALARS), que contribuem com o enriquecimento desse enfoque da Ciência das Redes e a educação em tempos de Covid-19. Sob uma outra perspectiva, mas também muito rica, o artigo 7 relata a experiência da construção da Rede Internacional de Educação OnLIFE - RIEOnLIFE, em parceria com a UAb Portugal. Nossos irmãos lusitanos nos fazem lembrar o artigo 12 originário da Universidade da Madeira que foi selecionado via edital. Assim também o foram o artigo 10 sobre as limitações da docência remota, baseado no discurso do sujeito coletivo e o artigo 11 que vem do Centro-Oeste do país, refletindo sobre um curso de artes do estado de Goiás via EaD. Por último, mas não menos instigantes, citamos os artigos 8 e 9. 0 artigo 8 , originário da UNIFESP, que numa época em que as metodologias ativas, as metodologias ágeis, as técnicas de sala de aula invertida estão tão em voga, traz-nos uma reflexão que nos leva a pensar sobre todo o processo educacional, discutindo a Aprendizagem Baseada em Projetos (ABP) em uma proposta formativa em EaD. Já o artigo 9 vem numa perspectiva de pensarmos fora da caixa, é uma pesquisa com participação de pesquisadores da Universidade Federal do Oeste do Pará, com resultados parciais de uma pesquisa em andamento para investigar as emoções durante a visualização de vídeoaulas preparadas com base na Teoria da Carga Cognitiva (TCC).

Com a grande quebra de paradigmas que vivenciamos com o advento da pandemia da Covid-19, do isolamento humano, do uso forçado e intensivo de Tecnologias da Informação e da Comunicação (TIC), de Ambientes Virtuais de Aprendizagem (AVA), tanto no trabalho como na educação, nada será como antes, queiramos ou não. A Educação a Distância não é mais dos especialistas, nem é dos que sempre resistiram a ela. Todos estamos tendo boas e más experiências com as TIC e a Educação, pois todos estamos dependendo delas para a sobrevivência humana.

A educação aberta em rede, baseada no diálogo do conhecimento, pode oferecer um novo horizonte de conhecimento e habilidades para enfrentar as mudanças nos cenários sociais, políticos e econômicos. Uma educação em rede democrática pode seguir por meio de uma educação dialógica - socrático-freiriana - com o objetivo de construir um processo de ensino aprendizagem por meio do diálogo e da troca de experiências entre os agentes envolvidos no processo educacional (MULLER; SOUZA, 2020). As ferramentas estão postas na 


\section{EmRede}

mesa, os instrumentos já são conhecidos de uma grande parcela dos humanos e se mostraram eficientes para o diálogo e para a sobrevivência. Agora, atuar e utilizar de forma aberta, híbrida, à distância ou presencial, sempre tendo claro a perspectiva de que tipo de educação em rede queremos construir, isso é o fundamental.

Queria muito agradecer a prof ${ }^{a}$ Dra $^{\mathrm{a}}$ Mára Lúcia Fernandes Carneiro, editora-chefe da revista EmRede, pelo convite de participar deste desafio de organizar este dossiê juntamente a ela. E agradecendo a essa professora, incansável lutadora pelo reconhecimento acadêmico da Educação a Distância, da mesma forma, agradecer à Associação Universidade em Rede (UniRede) pela oportunidade.

Eu não poderia deixar de citar também a Natana Lopes Pereira, minha orientanda de doutorado no Programa de pós-graduação em Engenharia e Gestão do Conhecimento da UFSC, na área de mídia do conhecimento, que aceitou essa árdua tarefa de me apoiar na editoria deste dossiê, e igualmente agradecê-la. Aproveito e estendo meus agradecimentos a todos os revisores, diagramadores, programadores e outras pessoas que colaboram e contribuem com tão importante publicação.

\section{REFERÊNCIAS}

CASTELLS, Manuel. A Sociedade em rede. 6 ed. São Paulo, SP: Paz e Terra, 2010.

MÜLLER, Felipe de Matos; SOUZA, Márcio Vieira de. FAKE NEWS: UM PROBLEMA MIDIÁTICO MULTIFACETADO. In: CONGRESSO INTERNACIONAL DE CONHECIMENTO E INOVAÇÃO, 8., 2018, Florianópolis. Anais do VIII Congresso Internacional de Conhecimento e Inovação (ciKi). Florianópolis: Lec/Egc-Ufsc, 2018. v. 1, p. 1-15. Disponível em: https://proceeding.ciki.ufsc.br/index.php/ciki/article/view/511. Acesso em: 18 dez. 2021.

MÜLLER, Felipe de Matos; SOUZA, Márcio Vieira de. The role of Knowledge Media in Network Education. International Journal For Innovation Education And Research, Dhaka, Bangladesh, v. 8, n. 7, p. 76-93, 7 jan. 2020.

OKADA, Alexandra et al. EDUCAÇÃO FORA DA CAIXA E FORMAÇÃO DE EDUCADORES EM REDE: inovação da educação 2030 com a escolarização aberta. In: TEIXEIRA, Clarissa Stefani et al. Educação fora da caixa: tendências internacionais e perspectivas sobre inovação na educação. 6. ed. Florianópolis: Trem da Ilha, 2021. p. 28-44. Disponível em: https://tremdailha.com.br/produto/livro-educacao-fora-da-caixa-6-tendenciasinternacionais-e-perspectivas-sobre-inovacao-na-educacao/. Acesso em: 13 dez. 2021.

SOUZA, Márcio Vieira de. Mídias Digitais, Globalização, Redes e Cidadania no Brasil. In: SOUZA, Márcio Vieira de; GIGLIO, Kamil. Mídias Digitais, Redes Sociais e Educação em Rede: Experiências na Pesquisa e Extensão Universitária. São Paulo: Blucher, 2015. p.15-45.

TEIXEIRA, Clarissa Stefani et al. Educação fora da caixa: tendências internacionais e perspectivas sobre inovação na educação. 6. ed. Florianópolis: Trem da Ilha, 2021. 264 p. Disponível em: https://tremdailha.com.br/produto/livro-educacao-fora-da-caixa-6tendencias-internacionais-e-perspectivas-sobre-inovacao-na-educacao/. Acesso em: $18 \mathrm{dez}$. 2021. 
TEIXEIRA, Clarissa Stefani; SOUZA, Márcio Vieira de (org.). EDUCAÇÃO FORA DA CAIXA: tendências internacionais e perspectivas sobre a inovação na educação. 4. ed. Florianópolis: Blucher, 2018.

i As publicações do Evento Educação Fora da Caixa podem ser acessadas nos sites dos Grupos de Pesquisa da UFSC: VIA - Estação do Conhecimento (https:// via.ufsc.br/educacao-fora-da-caixa/) e Grupo de Pesquisa Mídia e Conhecimento - GPM\&C (http://www.gpmc.ufsc.br/livros/). 